\title{
GEODETIC OBSERVATORY PECNY GNSS ANALYSIS SUPPORTING SOLID EARTH TIDE MODELLING
}

\author{
Jakub Nosek ${ }^{*}, 1,2$, Jan Douša ${ }^{2}$, Pavel Václavovic ${ }^{2}$, Lukáš Běloch ${ }^{2}$
}

"jakub.nosek@pecny.cz

${ }^{1}$ Brno University of Technology, Faculty of Civil Engineering, Institute of Geodesy, Veveři 331/95, Brno

${ }^{2}$ Geodetic Observatory Pecný, Research Institude of Geodesy, Topography and Cartography, Ustecka 98, Zdiby

\begin{abstract}
The TILDE project deals with local solid Earth tide (LSET) modeling based on direct LSET observations using long-term GNSS time series. Geodetic Observatory Pecný of the RIGTC contributes to the TILDE project by processing GNSS data. We collected GNSS data from 98 stations, which were divided into three subnetworks.

Quality control of all observational data was performed using advanced tools from the G-Nut library. Highaccuracy GNSS processing using the GNSS-PPP method was performed using REPRO_2020 precise products by the CODE. The results were coordinate displacement component data. Based on these data, LSET models from individual critical areas will be created. These LSET models can be used to assess the risks of earthquakes and volcanic activity caused due to LSET.
\end{abstract}

Key words

GNSS, Precise Point Positioning,solid Earth tide, GOP

\section{INTRODUCTION}

Earthquakes occur when fault stresses reach a critical level. Trigger stress due to tectonic movements is well known, but it can also occur during short-term non-tectonic stresses. Analyses of large earthquakes have shown that there exists a significant correlation between earthquakes and Earth tides [1]. Solid Earth tides (SET) are formed when the Earth's crust is moved due to gravitational attracting forces produced by external bodies, mainly the Sun and the Moon. So far, this correlation has been observed only indirectly by comparing earthquake catalogs and known positions of the Moon and Sun during earthquakes. The impact of SET at the local scale should be different in comparison with the globally SET models [2]. Accurate numerical modelling of local SET (LSET) is the critical parameter for analyzing the correlation between Earth tides and earthquakes. Direct observation of LSET will help better understand how tidal stresses are transmitted and cause earthquakes and volcanic activity.

We can effectively monitor LSET by Global Navigation Satellite Systems (GNSS). A suitable GNSS method for measuring SET is PPP because data from only one receiver are considered and thus not affected by other potentially not stable stations. On the other hand, PPP requires accurate modeling of the systematic errors with which it is affected, unlike relative GNSS methods [3].

Since December 2020, Geodetic Observatory Pecný (GOP) of Research Institute of Geodesy, Topography and Cartography (RIGTC) has contributed to the Tidal Interplate Litospheric Deformation of Earth (TILDE) project, submitted in response to the European Space Agency (ESA) called "An Innovative Concept For The Risk Assessment Of Geologic Hazards Using GNSS And Solid Earth Tides Modelling". The main goals of the TILDE project are analysis of SET from GNSS coordinate time series and deriving the relation between SET measurements and models with seismic and volcanic events.

This paper describes the processes and products that GOP / RIGTC contributes to the TILDE project solution. We present the procedures, methods, and analyses used to collect, control, and process GNSS data.

\section{RINEX DATA COLLECTION AND QUALITY CONTROL}

Many station candidates for the GNSS processing were identified and reviewed from publicly available networks. The candidate stations represented different tectonic areas, geological terrain, instrumentation, and global distribution. Critical data were available and correct metadata to maintain long-term consistency in GNSS results. 
After evaluating all the criteria, a total of 98 stations were selected. GNSS stations were divided into three basic sets (networks):

- Supersites $(4+4$ collocated stations $)$

- Global (65 stations)

- Regional (25 stations)

A few supersites were selected for those GNSS receivers that are co-located with gravimeters [4]. Supersites are located in tectonically stable areas, and for this reason, they are intended to be used for testing and for validating GNSS processing strategies in support of LSET estimation. The Global network contains GNSS stations globally distributed over World with long-term observations (2000-2020). Long-term GNSS observations ( $>18.6$ years) have been requested for determining the correlation between long periodic tides constituents and seismic/volcano activity [5]. The local network contains stations from geologically active areas, especially with earthquakes and volcano events-New Zealand ( 7 stations), south of Italy (18 stations). The map of the three defined networks using red (supersites), blue (global), and green (regional) dots is displayed in Fig. 1.

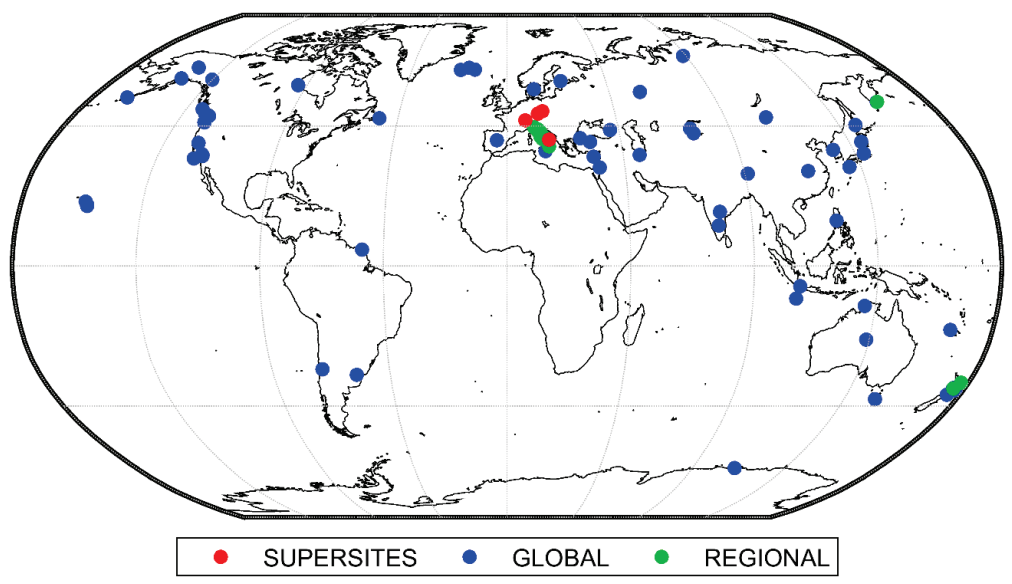

Fig. 1 Map of defined networks: Supersites, Global, and Regional.

Daily files in RINEX 2 format were downloaded to a local repository at GOP from various data repositories (e.g. IGS-CDDIS, IGS-BKG, EUREF-BKG, EUREF-ROB, GSSC-ESA, GEONET, UNAVCO).

The quality control (QC) is important to generate quality indicators. These indicators allow interpreting a resulting long coordinate time series. QC, which includes quantitative and qualitative control was performed using G-Nut / Anubis Pro 3.1 software [6], [7] for all collected RINEX2 files. The quantitative data control summarizes mechanically countable information (e.g. observed GNSS constellations, satellites, bands/frequencies, observation types/signals). The qualitative data control based on specific algorithms requires information about the position of GNSS satellites. Important input is the navigation files in the RINEX format. We used the GOP consolidated broadcast navigation data in RINEX3 format [8]. The results of qualitative control are e.g. code multipath, phase cycle-slips, and clock-jumps and the ratio of have/expected observations. The result of QC were Anubis' XTR/XML output files suitable for visualizing. For practical reasons, mainly were visualised these key parameter indicators:

- Minimum observed elevation angle

- $\quad$ Available GNSS constellations

- Data file length

- Ratio of have / expected number of observations above the horizon

- Ratio of have / expected number of observations above the 15 degree elevation angle cut-off

Fig. 4 shows an example of QC visualizations. Excellent and stable performance can be seen at station POL2 in 2004 (Fig. 2 above). In 2019, CAS1 tracked 3 GNSS (GPS, GLONASS, Galileo) with 0 degree elevation angle cut-off which has been recommended within International GNSS Service (IGS) in 2004. Fig. 2 (bottom) displays an example of a highly unstable data tracking station PIMO in 2001. 


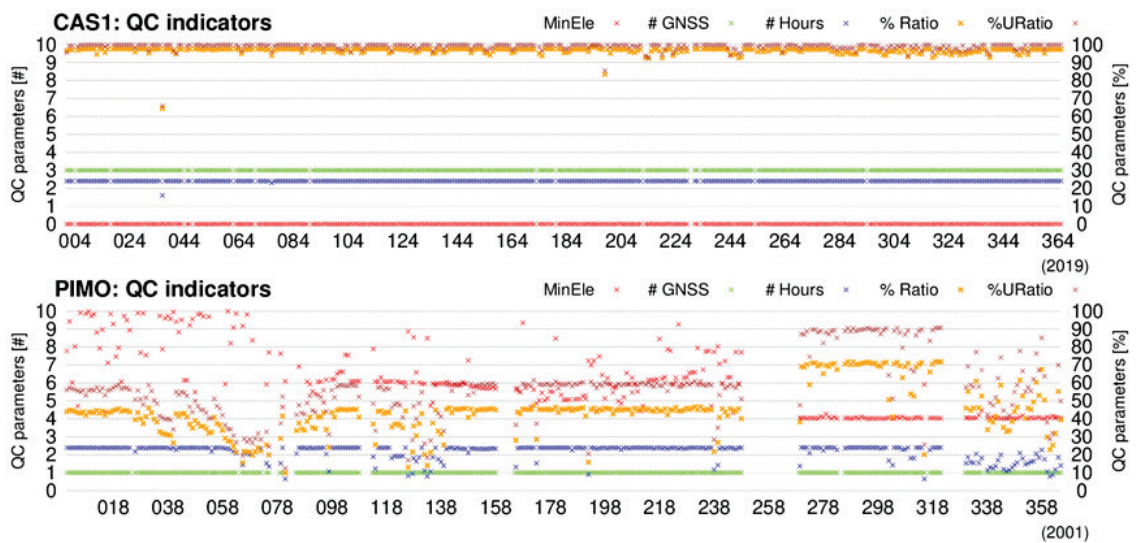

Fig. 2 Examples of visualizations of QC results.

\section{GNSS DATA PROCESSING}

For LSET modelling analysis were required 2 main GNSS processing outputs - daily stations coordinates and 3 hour coordinates. It was also necessary to process GNSS data without (SET-OFF) the standard SET model based on International Earth Rotation and Reference Systems Service (IERS) 2010 Conventions. Coordinates repeatibility was estimated using GNSS-PPP processing variant with IERS2010 SET modelling. Before processing, we had to test and select optimized processing strategies, models and products.

\section{Selecting precise products}

Fully consistent precise products (satellite orbits and clock) are needed for high-accuracy long-term GNSS PPP analyses. There are several sources of precise GNSS orbits and clock products. Precise products are provided by International GNSS Service (IGS) Analysis Centres (AC), or the product is generated directly by IGS. The main advantage of the IGS product is the higher robustness and accuracy compared to individual ACs products. Operational products are irregularly disrupted by any changes in models, processing strategy, and reference frame realization. A re-processing product has been thus developed and regularly generated based on a homogeneous reanalysis of historical observations. We initially identified and evaluated candidates for the precise products summarized in Tab. 1.

Tab. 1 GNSS precise products - candidates information.

\begin{tabular}{cccc}
\hline Product & Availability & Products types & Constellations \\
\hline IGS Final & 1994-present & EPH, ERP, CLK $(5 \mathrm{~min}, 30 \mathrm{sec})$ & GPS + (GLONASS) \\
IGS Repro2 & $1994-2013$ & EPH, ERP, CLK $(5 \mathrm{~min})$ & GPS + GLONASS \\
AC Final & $1994-$ present & EPH, ERP, CLK $(5 \mathrm{~min}, 30 \mathrm{sec})$ & GPS + (GLONASS $)$ \\
AC Repro2 & $1994-2013$ & EPH, ERP, CLK & GPS + (GLONASS $)$ \\
CODE Repro_2015 & $1994-2014$ & EPH, ERP, CLK $(5 \mathrm{~min}, 30 \mathrm{sec})$ & GPS + GLONASS \\
CODE Repro_2020 & $1994-2020$ & EPH, ERP, ATT, BIA, CLK $(30 \mathrm{~s}, 5 \mathrm{~s})$ & GPS + GLONASS + Galileo \\
\hline
\end{tabular}

After the kick-off of the TILDE project, we compared the accuracy of Repro2 / operational products produced by IGS, CODE, ESA, JPL, and CNES. The analysis showed that precise orbits and clock products by Center for Orbit Determination in Europe (CODE) are suitable candidates for our GNSS-PPP processing. However, in April 2021, CODE completed the REPRO_2020 solution as a contribution to IGS Repro3, which became the best candidate for our campaign due to:

- Homogeneous reprocessing precise orbit and clock products (1994-2020) and official Galileo satellite antenna phase centre models,

- GPS, GLONASS, Galileo systems supported with precise orbits and clocks ( $5 \mathrm{~s}, 30 \mathrm{~s})$,

- Code and phase biases and satellite attitude data possible ambiguity-fixed PPP. 
CODE REPRO_2020 removed inconsistencies in operational products due to the introduction of ITRF2014 and related PCO / PCV models in 2017. We tested the internal repeatability of PPP using CODE REPRO_2015 and CODE_2020 precise products (summarized in Tab. 2).

Tab. 2 Yearly repeatability comparison of CODE Repro2 and Repro3 (3D standard deviations).

\begin{tabular}{ccc}
\hline Year & Repro3 (CODE_2020) $[\mathrm{mm}]$ & Repro2 (CODE_2015) $[\mathrm{mm}]$ \\
\hline 2001 & 6.4 & 8.1 \\
2005 & 5.3 & 5.8 \\
2010 & 6.5 & 6.4 \\
2015 & 5.4 & 5.3 \\
2020 & 5.0 & 5.6 \\
\hline
\end{tabular}

\section{Optimizing PPP processing strategy}

For long-term coordinate analysis, GNSS data have to be processed consistently throughout the processing period. Firstly, we defined strategy of PPP processing for our campaign. As already mentioned, we used precise orbits and clock products provided by CODE. For estimating the LSET parameters, we use IERS2010 standards and conventions, included solid Eath tides, pole tides, and ocean tide loading. For PCO/PCV modelling we use igsR3_2077.atx model from IGS repro3 campaign. Modelling of tropospheric delay effect included estimates of Zenith Total Delay (ZTD) and troposphere horizontal linear gradients. We used the Square root forward filter for solving the normal equations, which is a more numerically stable alternative to the traditional Kalman filter. Initical convergence we eliminated using the backward smoothing algorithm, which can lead to comparable accuracy as that from the integer ambiguity resolution [16]. Basic characteristis of GNSS-PPP processing strategy are sumarized in the Tab. 3. For GNSS-PPP processing we utilized the G-Nut/Geb software.

Tab. 3 Processing strategy, models, and used precise products.

\begin{tabular}{|c|c|}
\hline Item & Parameter \\
\hline Estimator & Square root filter / RTS backward smoother \\
\hline Observations & Pseudorange and carrier phase observations \\
\hline Constellations & GPS + GLONASS \\
\hline Sampling rate & $30 \mathrm{~s} / 150 \mathrm{~s}$ \\
\hline Elevation cut-off & $7^{\circ}$ \\
\hline Observation weighting & Elevation dependent $1 / \sin (\text { elevation })^{\wedge} 2$ \\
\hline Satellite orbits/clocks & CODE repro3 (fixed) \\
\hline Ionospheric delay & Elliminated using the ionosphere-free combination \\
\hline Tropospheric delay & Zenith hydrostatic delay: Saastamoinen \\
\hline & $\begin{array}{l}\text { Zenith wet delay: estimated with } 0.5 \mathrm{~mm} / \mathrm{sqrt} \text { (hour) } \\
\text { random walk process noise }\end{array}$ \\
\hline Receiver clock offset & Estimated as white noise \\
\hline Phase-windup & Corrected \\
\hline Attitude of satellites & Nominal models (eclipsed satellites not used) \\
\hline Antenna phase centers & Corrected with igsR3_2077.atx file \\
\hline \multirow[t]{3}{*}{ Tides } & IERS Convention 2010 \\
\hline & Solid Earth tide \\
\hline & $\begin{array}{l}\text { Ocean tide loading based on FES2014b model } \\
\text { Pole tides based on pole coordinates }\end{array}$ \\
\hline Ambiguity & Float (convergence eliminated by the smoothing) \\
\hline
\end{tabular}

It was necessary to process a lot of data (20-year daily data from 98 stations), so we looked for suitable sampling to achieve high accuracy at efficient CPU load. We compared several variants of processing results using different data sampling rates: $30 \mathrm{~s}, 60 \mathrm{~s}, 90 \mathrm{~s}, 150 \mathrm{~s}, 300 \mathrm{~s}, 600 \mathrm{~s}$, and $900 \mathrm{~s}$. Fig. 3 shows an impact of data sampling interval on the processing time during 20 years (above) and impact on the positioning accuracy (below). Based on comparison, we selected 150s sampling for daily LSET estimation variants and 30s sampling for $3 \mathrm{~h}$ LSET estimation variants. 


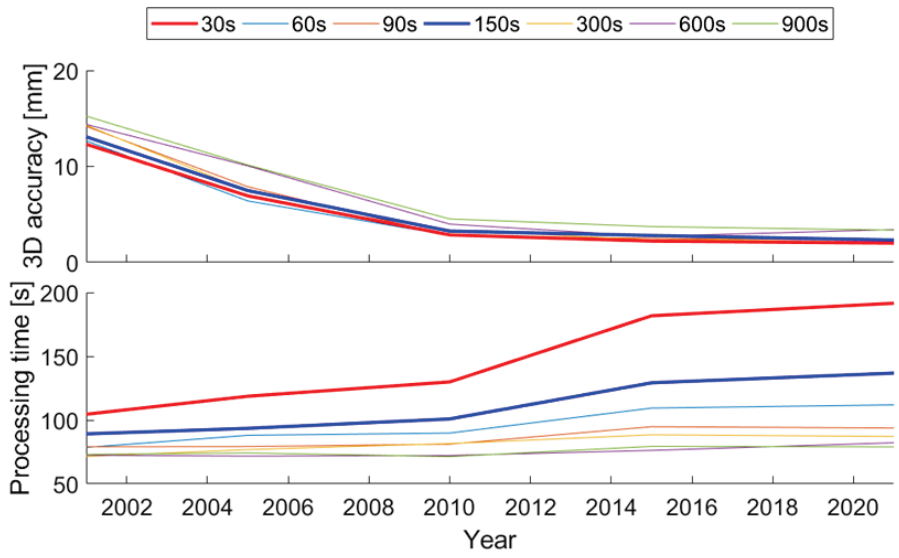

Fig. 3 Examples of visualizations of QC results.

Finally, processing included 2 variants with $1 \mathrm{~d}$ and $3 \mathrm{~h}$ sampling of LSET estimation IERS2010 SET model not included). Reference coordinates of stations (+ coordinate repeatibility) were estimated using GNSS-PPP processing including IERS 2010 SET model. The time required to process all GNSS data was about 14 days $(\sim 230$ CPUs / 1200 GB RAM).

\section{Post-processing, products for LSET estimation}

Original G-Nut/Geb output files represent daily/3hours outputs in the format of site-specific parameter file using the G-Nut/Geb native format, daily solution file in the SINEX standard format, and daily G-Nut/Geb log file. The parameter file includes the most important user parameters such as stations coordinates, tropospheric delays and receiver clocks. The format contains the results of all the processing epochs as provided by the Kalman filter/RTS backward smoother. We used G-Nut/Apep software to post-process the daily/3hours output files when performing collecting and filtering original epoch-by-epoch and time-series analysis for linear trend estimates, residuals check, and repeatability estimates. The post-processing procedure resulted in the format defined particularly for the resulting exchange between the partners in the project. The format includes station coordinates (XYZ and BLH), internal estimates of velocities, and the reference epoch of the reference coordinates for site-specific linear model reconstruction.

For visualization of results, we created a dedicated web at least within the duration of the TILDE project (http://www.pecny.cz/TILDE/). Fig. 4 shows an example of LSET visualizations. LSET North-East-Up displacement components at the WZR station in January 2020 (above) and at station ACAE in 2019 (below).
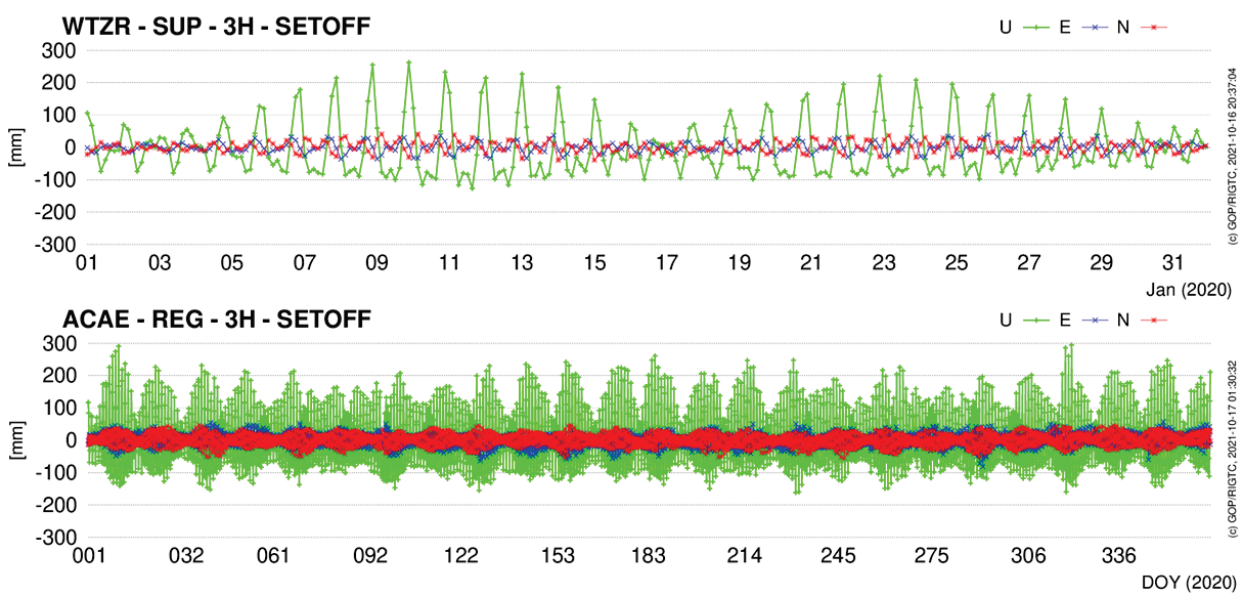

Fig. 4 LSET displacement component at the WTZR (above) and ACAE (below) GNSS stations. 


\section{CONCLUSION}

Local solid Earth tides (LSET) modeling can have a positive impact on the preparation of strategies to reduce the vulnerability of geological hazards and response coordination. Current GNSS capabilities allow directly measuring LSET around the world. The GNSS-PPP method has proven to be suitable for large-scale LSET estimation campaigns.

We collected GNSS data from 98 GNSS stations from 2000-2020. According to their dispositions, the GNSS stations were divided into three subnetworks: Supersite, Global, and Regional. We performed GNSS data quality control using G-Nut / Anubis and a consolidated navigation data archive as an input. The latest reprocessed REPRO_2020 precision products by CODE were used for GNSS-PPP processing. Compared to IGS/ACs repro2/ operational products, CODE REPRO_2020 products showed the best performance for long-term high-accuracy GNSS analysis.

Before massive GNSS-PPP processing, we tested the effect of observational data sampling rate on estimated parameters. Before massive GNSS-PPP processing, we tested the effect of observational data sampling rate on process performance (accuracy, processing time). We evaluated the 150s sampling frequency for daily LSET estimation and 30s for 3-hour LSET estimation as optimal.

The results of GNSS-PPP processing and post-processing are LSET North-East-Up coordinate displacements data. Future work will be an estimate of LSET models for each area of interest based on this data.

\section{Acknowledgement}

Presented work is part of the TILDE project, which is funded by the NAVISP contract NAVISP-EL1-047 "An Innovative Concept For The Risk Assessment Of Geologic Hazards Using GNSS And Solid Earth Tides Modeling". This article was supported by faculty research project FAST-J-21-7178 "Development of a strategy for fast GNSS-PPP ambiguity resolution" of internal grant system BUT. The authors gratefully acknowledge the CODE for release the latest CODE repro3 satellite orbits and clocks.

\section{References}

[1] Métivier L, de Viron O, Conrad CP, Renault S, Diament M, Patau G. Evidence of earthquake triggering by the solid earth tides. Earth and Planetary Science Letters [Internet]. 2009 [cited 2021Nov.27];278(3-4):370-375. Available from: https://linkinghub.elsevier.com/retrieve/pii/S0012821X08007723.

[2] Watson C, Tregoning P, Coleman R. Impact of solid Earth tide models on GPS coordinate and tropospheric time series. Geophysical Research Letters [Internet]. 2006 [cited 2021Nov.27];33(8). Available from: http://doi.wiley.com/10.1029/2005GL025538

[3] Václavovic P, Nesvadba O. Comparison and assessment of float, fixed, and smoothed precise point positioning. Acta Geodynamica et Geomaterialia [Internet]. [cited 2021Jun.9];:329-340. Available from: http://www.irsm.cas.cz/index en.php?page=acta detail doi\&id=358

[4] Pahlevi AM, Prijatna K, Meilano I, Sofian I. INVESTIGATION OF THE SOLID EARTH TIDE BASED ON GPS OBSERVATION AND SUPERCONDUCTING GRAVIMETER DATA. JURNAL ILMIAH GEOMATIKA [Internet]. 2017Jan.12 [cited 2021Nov.27];22(1):29-35. Available from: http://jurnal.big.go.id/index.php/GM/article/view/488

[5] Zaccagnino D, Vespe F, Doglioni C. Tidal modulation of plate motions. Earth-Science Reviews [Internet]. 2020 [cited 2021Nov.27];205. Available from: https://linkinghub.elsevier.com/retrieve/pii/S0012825220302257

[6] Václavovic P, Douša J. G-Nut/Anubis: Open-Source Tool for Multi-GNSS Data Monitoring with a Multipath Detection for New Signals, Frequencies and Constellations. In: IAG 150 Years [Internet]. Cham: Springer International Publishing; 2016 [cited 2021Jun.9]. pp. 775-782. (International Association of Geodesy Symposia). Available from: http://link.springer.com/10.1007/1345_2015_97

[7] Douša J, Václavovic P. G-Nut/Anubis Version 3 - User manual. 2021. Available at: https://gnutsoftware.com/themes/gnut/assets/files/anubis_manual.pdf?v3

[8] Douša J. GOP's consolidated multi-GNSS navigation data archive. Royal Observatory of Begium. 2018 Available from doi: $10.24414 / \mathrm{c} 4 \mathrm{ba}-\mathrm{kf1} 6$ 